\title{
The syntax of relative clause constructions in Runyankore-Rukiga: A typological perspective
}

\author{
Allen Asiimwe \\ Department of African Languages, Makerere University, Uganda \\ E-mail: asiimwea94@gmail.com
}

\begin{abstract}
This paper discusses the morphosyntactic properties of relative clause constructions in the Runyankore-Rukiga language cluster (Bantu, JE13/14, Uganda). Relative clauses in this paper are categorized into nominal and clausal relatives on the basis of their exhibited morphosyntactic properties. The nominal relative clause category comprises elements which have been previously regarded as adjectives (Morris and Kirwan 1972; Taylor 1985) which include some color terms among other lexical items. The second category, namely clausal relatives, is subcategorized into subject and object clausal relatives. The subject clausal relative is realized within the subject nominal prefix by differential tone marking while the object clausal relative is an obligatory agreement-bearing complementizer which stands alone in agreement with the object antecedent. This paper describes the properties and use of the object relative marker as it has previously been regarded as a demonstrative or a pronoun. The paper offers an alternative position to the status of the object relative clause marker, proposing that it is not a pronoun equivalent to the English Wh-relative pronoun, and that it is not a demonstrative per se, but rather an agreement-bearing complementizer that heads a CP. The paper further asserts that the augment is not a relative clause marker as it is stated in Morris and Kirwan (1972) and Taylor (1985) but expresses a restrictive relative clause when present. As part of syntax, the paper discusses agreement properties in relative clause constructions and reports that a clausal relative takes the agreement of the head of the relative clause, but this is not always the case since anti-agreement cases are reported. Data for the analysis comes from authentic written materials and elicited constructions.
\end{abstract}

Keywords: Nominal relatives; clausal relatives; augment; agreement; Runyankore-Rukiga.

\section{Introduction}

Runyankore-Rukiga is generally understudied compared to other Bantu languages such as Shona (S10) ${ }^{1}$, Kiswahili (G40), Zulu (S42) and Luganda (JE15). There is little linguistic information available on Runyankore-Rukiga. Most of the available linguistic work is in the form of unpublished theses and therefore not accessible to the general readership. For any

\footnotetext{
${ }^{1}$ Classification of Bantu languages is based on Maho (2009).
} 
language that is not well described, a systematic description of structure and functions of specific phenomena should precede any attempt to offer theoretical analysis. I therefore generally offer a descriptive morphosyntactic analysis of relative clause constructions in Runyankore-Rukiga. This is in line with language typologists (e.g, Shopen 1985) who posit that language descriptions for (cross-)linguistic variations should precede any attempts to offer formal theoretical analysis. This paper intends to contribute to the existing literature on Bantu relative clause constructions and offer data for typological, comparative and ultimately formal theoretical studies.

In this paper, relative clauses are divided into two categories, namely, nominal clausal relatives and clausal relatives. Nominal clausal relatives form a category of words which have previously been taken to be adjectives. Under this category we find color terms such as -rikutukura 'which is red' and other lexical items like -rikufuka 'which is cold', among others. These words present verb-like morphological properties that are distinct from those of true adjectives in Runyankore-Rukiga and therefore need to be put in a separate category.

Properties of clausal relatives are discussed bearing in mind what is already provided in literature, especially for other Bantu languages as regards the status of the object clausal relative marker, agreement properties and subject inversion phenomena. As will be discussed in section 5 , for example, the object relative clause marker switches agreement between the internal locative noun and the locative element that heads the locative phrase which has been inverted. This will later be analyzed in relation to Demuth and Harford's (1999) assertion drawing from Sesotho (S32) data that, agreement occurs when an element has been raised to Spec-IP. An element remains in the Spec-VP position if there is no agreement with the subject antecedent. Thus, an element can only trigger agreement when it has been raised to Spec-IP. The paper makes a brief attempt based on Runyankore-Rukiga data to examine whether an object that has been inverted can be analyzed following Demuth and Harford's (1999) assertion. Either the internal head noun of the structural subject, or the locative element that precedes the head noun can occupy the Spec-IP slot through an agreement switch as exemplified in (1.a-c) and discussed in section 5. Data for the analysis comes from authentic Runyankore-Rukiga written materials such as novels and the translated Runyankore-Rukiga Bible (the 1964 version). Some of the data is elicited and cross-checked through consultations with native speakers. However, all the glosses are mine ${ }^{2}$.

\author{
a. omw'ihang'ómw' áríkutúura \\ o-mu i-hanga o-mu a-ri-ku-tuur-a \\ AUG-18 5-country AUG-18 SBJ.1SG-be-INF-stay-FV \\ "In the country where she/he stays." \\ b. omw'ihang' ery' áríkutúúrámu \\ o-mu i-hanga e-ri a-ri-ku-tuur-a=mu \\ AUG-18 5-country AUG-5 SBJ.1SG-be-INF-stay-FV=18.ENC \\ "The country in which she/he stays."
}

\footnotetext{
${ }^{2}$ Abbreviations used in the glosses are as follows: $\mathrm{APPL}=$ applicative; $\mathrm{ASP}=\mathrm{Aspect} ; \mathrm{AUG}=$ augment; $\mathrm{COP}=\mathrm{copula}$; $\mathrm{DEM}=$ demonstrative; $\mathrm{INF}=$ infinitive; LOC $=$ Locative; $\mathrm{NEG}=$ Negation; $\mathrm{PST}=$ past; PASThst $=$ hesternal past: recent past; PASTim = immediate past tense; PASTrm = far past tense; PFV = perfective aspect; FV = final vowel; STAT = stative; $\mathrm{SBJ}=$ subject; $\mathrm{SBJV}=$ subjunctive mood; $\mathrm{ENC}=$ enclitic $\mathrm{REL}=$ relative; $\mathrm{NIV}=\mathrm{New}$ International Version; $\mathrm{SG}=$ Singular Person; $\mathrm{PL}=$ Plural person.
} 


$\begin{array}{lll}\text { c. eihang' } & \text { éry' } & \text { áríkutúúrámu } \\ \text { e-i-hanga } & \text { e-ri } & \text { a-ri-ku-tuur-a=mu } \\ \text { AUG-5-country } & \text { AUG-5 } & \text { SBJ.1SG-be-INF-stay-FV=18.ENC } \\ \text { "The country in which she/he stays." }\end{array}$

This paper discusses relative clause constructions in Runyankore-Rukiga in two categories, namely nominal relatives and clausal relatives. Each of these categories is discussed in turn, starting with nominal relatives in section 2 . In section 3 , the second category of relative clauses is discussed, where two relative clause formation strategies are involved leading to subject and object relative clause categories. In section 4, the (non-)occurrence of the augment in relative clauses is examined where evidence is provided against the analysis of the augment in Runyankore-Rukiga as a relative clause formation strategy, because the augment can be dropped but the relative clause meaning is maintained. Instead, I argue that the presence of the augment triggers a restrictive interpretation of the modified head noun. Section 5 examines the agreement phenomenon in relative clause constructions mainly drawing on examples from locative constructions. The conclusion to the paper is provided in section 6 .

\section{Nominal relatives}

The category of nominal clausal relatives (a term adopted from Asiimwe (2014)) ${ }^{3}$ is comprised of color terms such as -rikutukura 'red', -rikwiragura 'black' and other lexical elements including -rikwosya 'which is hot', and -rikutagata 'which is warm' and others. These lexical items, which in previous research are commonly rendered as adjectives, present complex forms with clausal features. Taylor (1985) for instance considers these elements as adjectives or as verb stems or forms of adjectival phrases containing a relativized verb. Reading from the various terms used in Taylor (1985), there seems to be no clear criteria or systematic analysis as regards the categorial status of these words. The lexical items considered under this category are morphologically complex with clausal morphological features. Indeed, what constitutes the category 'adjectives' in Bantu languages has been contested (see among others, van der Spuy 2001; Mojapelo 2015; Lusekelo and Mpobela 2017). It is on morphological grounds that I categorially place them under their own class. The examples in (2.a-b) indicate that the morphology of the modifiers of the noun present variable morphological forms, which therefore leads to the argument that they do not belong to the same category.

There is no agreed upon definition of adjectives. Moreover, the term 'adjective' is often used to cover a wide range of expressions which modify nouns (e.g. Rubongoya 1999; Baker 2003; Martinez-García 2014), although Dixon's (2004) definition of adjectives takes into consideration grammatical and semantic criteria. An English 'adjective' can be interpreted as an adjective, a possessive expression, a relative, or an enumerative in Runyankore-Rukiga. Lexical items under the general category 'adjectives' can be derived from nouns, verbs, or even adjectives (Segerer 2008). Regardless of the structure, color terms are often taken semantically to belong to the category of adjectives. Looking at the structure of the adnominals in (2.a-b), the morphological structure of the adnominal adjective kihango 'big' in (2.a) is different from

\footnotetext{
${ }^{3}$ The term nominal relative is also used in Poulos and Louwrens (1994).
} 
that in (2.b) which is kirikutukura 'red'. The modifying word in (2.a) exhibits the typical structure of an adjective while the one in (1.b) does not ${ }^{4}$.

$\begin{array}{lll}\text { a. } & \text { ekikopo } & \text { kihángo } \\ & \text { e-ki-kopo } & \text { ki-hango } \\ & \text { AUG-7-cup 7-big } \\ & \text { "A big cup." } \\ \text { b. } & \text { ekikopo kiríkutukura } \\ & \text { e-ki-kopo ki-ri-ku-tukura } \\ & \text { AUG-7-cup 7-be-INF-red' } \\ & \text { 'a red cup' } \\ & \text { "A cup which is red." }\end{array}$

Adjectives in Bantu languages are structurally composed of an adjectival root and a prefix which is influenced in terms of gender and number (Newman 2000) by the shape of the noun class prefix of the modified lexical head noun whether explicit or implied. The modifying word in (2.b) presents a complex form with -ri-ku- morphemes which depict clausal properties. I therefore argue in this paper that words which present this kind of morphological structure are not adjectives but nominal relatives based on the morphosyntactic evidence presented here.

According to Sportiche, Koopman, and Stabler (2013: 11), "a category is a set of expressions which all behave the same way". In terms of morphology, kihango 'big' in (2.a) has two morphemes: the prefix -ki- and adjectival root -hango. The nominal agreement prefix of an adjective in Bantu languages is generally homogenous to the class prefix of the head noun. In the second example (2.b), kirikutukura is complex with ri-ku as verbal morphemes. Hence, when one compares the morphological makeup of the two adnominal modifiers, both of which have been previously regarded as adjectives, kirikutukura does not present the morphological structure of an adjective, and hence one can argue that it belongs to a different category. In the examples in (3.a-b), other words with the same morphological make as the color term rikutukura in (2.b) are presented:

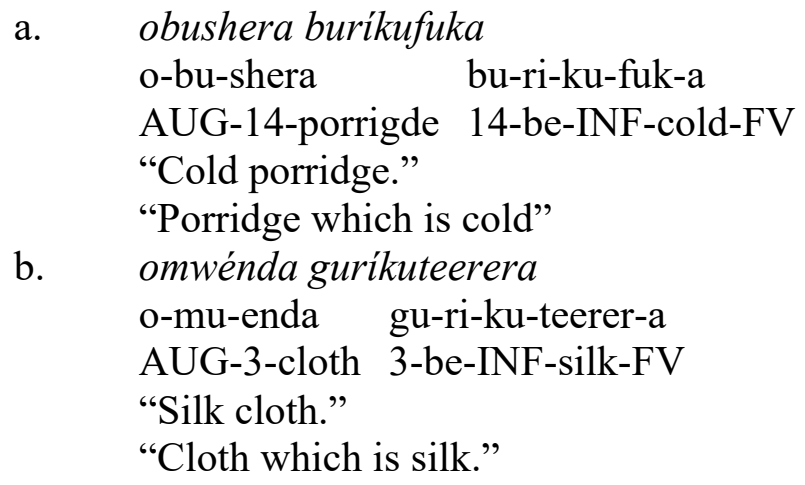

The adnominal modifier forms exemplified in (3.a-b) also present distinct structural forms from true adjectives such as -hango 'big' (in 2.a). In addition to an agreement prefix, the category of modifiers exemplified in 2(b) and 3(a-b) contain -ri- which is the be-verb form, and the infinitive marker $-k u$-. Examining these forms from a morphological point of view, the words

\footnotetext{
${ }^{4}$-riku- is presented as a single morph and glossed as present continuous/progressive (PC) in Taylor (1985:2)
} 
exhibit both nominal and verbal properties. In other words, they are lexicalized elements portraying both nominal and clausal properties. The nominal modifiers as indicated in (3.a-b) are considered nominal on the basis of the availability of the inflectional morpheme $-k u-$, which exhibits an ambivalent character of being nominal and verbal (see also Asiimwe 2014). In addition, clausal properties of the category stem from the $b e$-verb -ri-, which takes a stem as a nominal complement. Usually the translation for such words is misguided by the English versions ${ }^{5}$, which are typically adjectives, in that often -rikufuka (3.a) is rendered as 'cold'. However, following the morphological structure of the word, the English translation would better be interpreted as 'which is cold' for the fact that the structure is not entirely an adjective but contains clausal elements. Even when the meaning is clearly relative, the translations rendered mostly follow the English forms.

Even so, on the basis of morphology, note that in the case of kihango (2.a), or murungi (4.a), the adnominal adjective exhibits the nominal prefix in the inflectional morphology similar to the prefix of the head noun, which is a typical characteristic of adjectives in Bantu languages (a list of 'true' Runyankore-Rukiga adjectives adapted from Taylor (1985: 174) is given in (5)). On the other hand, the word forms categorized here as nominal relatives do not exhibit such morphological property. For instance, the agreement prefix forms of color terms are not always identical with the class prefix of the head noun (4.b). Instead of $m u$ - (as in (4.a)) the concord form is $g u$ - (4.b). This disparity provides further evidence that gurikwiragura (4.b) does not belong to the category of adjectives, at least by show of its morphology.
a. omwénda murungi
o-mu-enda mu-rungi
AUG-3-cloth 3-beautiful/good/nice
"A beautiful cloth."
b. omwenda guríkwíragura
o-mu-enda gu-ri-ku-iragur-a
AUG-3-cloth 3-be-INF-black-FV
"A black cloth."
"A cloth which is black."

All the words given in the list in (5) take a nominal prefix that is identical to the class prefix of the head noun because that is a morphological feature of true adjectives. I therefore depart from the classification criteria where words are categorized as adjectives on the account of their semantics.

(5)

Adjective root
-hango
-kye
-raingwa
-gufu
-kuru
-to
-sya
-sha

$\begin{array}{ll}\text { meaning } & \text { Adjective root } \\ \text { 'big' } & \text {-rungi } \\ \text { 'small' } & \text {-bi } \\ \text { 'tall' } & \text {-ingi } \\ \text { 'short } & \text {-yonjo } \\ \text { 'old' } & \text {-rofa } \\ \text { 'young' } & \text {-shaija } \\ \text { 'new' } & \text {-kazi } \\ \text { 'empty' } & \end{array}$

meaning 'good, beautiful'

'bad, ugly'

'many, much'

'clean'

'dirty'

'male'

'female'

\footnotetext{
${ }^{5}$ See the first line of translation e.g., in examples in (2.b).
} 
-bisi

'raw'

According to Dixon (2004), all words which denote color, size, shape, dimension, or age, among others, are regarded as adjectives. The classification should put into consideration the morphological characteristics of individual words. This is the criteria that I have followed to identify words which present more than what is expected of an adjective and place them in a distinct category of nominal relatives.

There are other forms which do not exhibit the -ri-ku- morphology and yet they exhibit relative meaning. These forms are illustrated in (6). This category of nominal modifiers may take an agreeing prefix homogenous to the class prefix of the head (6.a(i)-(ii)). The modifier -gumire takes the prefix of the head noun ru-. In the examples in (6.b) there is no -ri-ku-which, as we have seen above, are used in the formation of the nominal relative words, and are nonhomogenous with the class prefix of the head noun. Instead -gumire 'which is difficult' takes a perfective marker -ire which is also used in stative verb formations (Nurse 2003, 2008). All these examples, as those which show the verbal morphemes -riku-, would be translated as adjectives in previous research following their semantics.

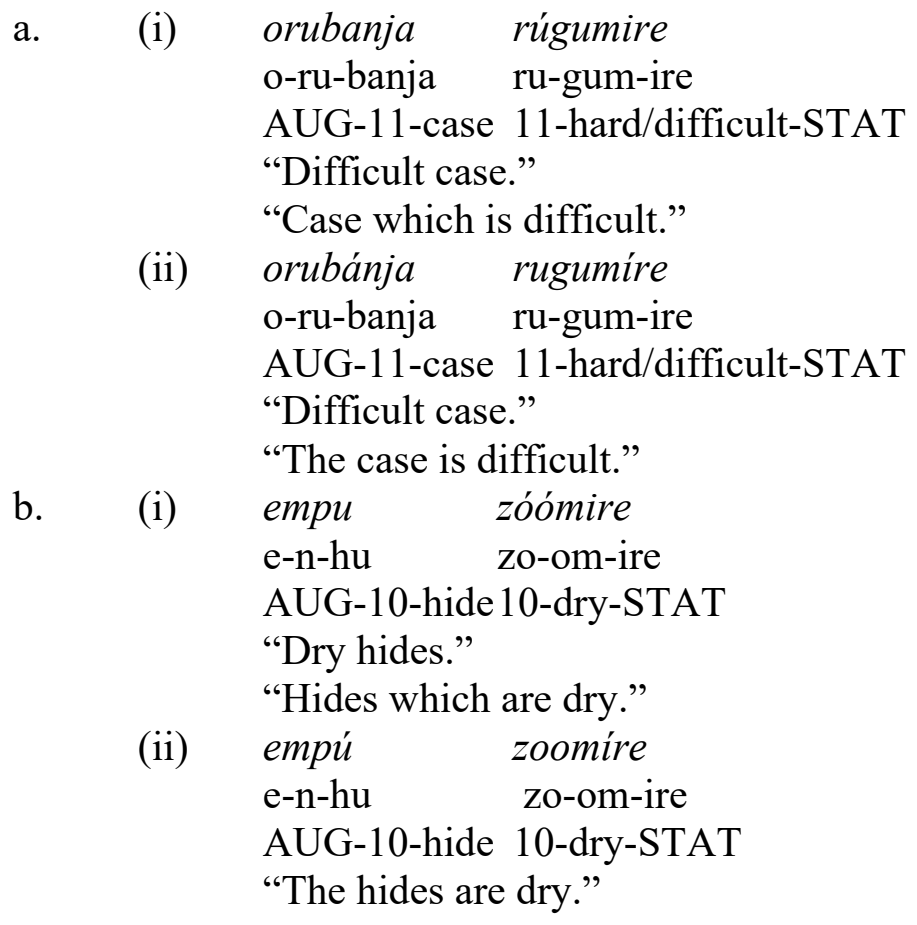

The above exemplified forms can also form complete sentences (see 6a(ii), b(ii)). This is enabled by a shift in the high tone from the agreeing prefix to the vowel of the perfective -ire morpheme which results in a stative construction. When a true adjective such as -hango plays the predicative role, a copula verb $n i$ is explicit, as we see in (7). This further indicates that the modifiers such as -omire (6.b(ii)) and -rungi (7) are morpho-syntactically distinct.

$$
\begin{aligned}
& \text { Omwénda ni murungi } \\
& \text { o-mu-enda ni mu-rungi } \\
& \text { AUG-3-cloth is 3-good/beautiful } \\
& \text { "The cloth is good/beautiful." }
\end{aligned}
$$


The forms presented in 6.a(i) and 6.b(i) are often interpreted as adjectives, yet they present a morphologically more complex state, and I argue that such forms should not be treated as adjectives because they exhibit clausal relative meaning.

Another feature to consider is that this category of words allows for a suffix which is used to derive other word forms. The suffix can be in the form of an applicative exhibiting intensifier meaning or a causative (8.a-c) and a final vowel. For example, as we can observe, rikutukurira kimwe 'which is hot-red' (8.a) is derived from -rikutukura 'which is red'.

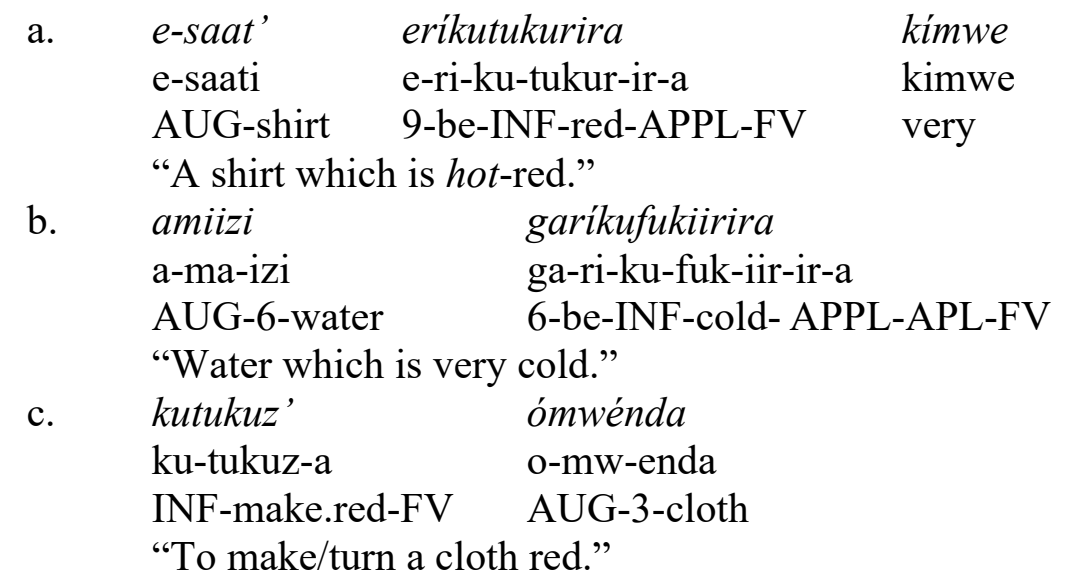

For intensity, the adverb kimwe 'very' is added to the derived form of the nominal relative (8.a) or the verb carries an applicative -ir- (8.b). A causative can also be derived (8.c). Note however that -tukuz-a 'make red' can also become ku-tukur-ir-za kimwe 'to intensify the red color'. To add an intensifier meaning, the verb permits an applicative -ir-morpheme before the causative (cf. Asiimwe 2014). Without the applicative -ir-, adding an intensifier word 'kimwe' renders the construction ungrammatical (9). Such derivations with verbal affixes are not possible with real adjectives such as -rungi 'good/beautiful' or -kye 'small'. Otherwise, an unacceptable form is formed. For instance, if an intensifier morpheme which takes the form of an applicative is added to -rungi: *okurungira kimwe 'to make very beautiful'. Instead a verb form is used: $o$ ku-boner-a 'to be beautiful/good' to o-ku-boner-er-a kimwe 'to be very beautiful'.

$$
\begin{array}{lll}
* a-m a-i z i & g a-r i-k u-f u k-a & k i m w e \\
\text { AUG-6-water } & \text { 6-be-INF-cold-FV very } \\
\text { Intended: "Water which is very cold." }
\end{array}
$$

A further argument to make is that on the basis of the presence of the inflectional morpheme $k u$ - which possesses nominal properties, nominal relatives can be verbalized. Hence, e-ki-ri$k w$-iragur- $a$ '(something) which is black' can become $o$ - $k w$-iragura 'to be black' or even a causativised form is derivable $o$ - $k w$-iraguz- $a$ 'to make black'. On the basis of the dual character of $-k u$-, I posit that the root is the nominal complement (to be categorized as an NP of the inflectional category) of the $b e$-verb -ri-.

Note that there is no dedicated marker for nominal relatives. The relative clause meaning is embedded in the agreement prefix morph that precedes the -ri-ku morphemes; hence, a portmanteau morph. However, there is an exception with nouns in classes 1 and 9 (10.a-b). As 
also observed in Taylor (1985: 141), nouns in these two classes show no morpheme break between the class marker and the augment. One morpheme represents the augment, the relative clause meaning and the class marker. The noun class in which the relative meaning is embedded coalesces with the augment, leading to one affix simultaneously representing three distinct morphs on the surface.
a. omwishiky'
oríkwéra
o-mu-ishiki
o-ri-kw-er-a
AUG-1-girl
AUG.1.REL-be-INF-light-FV
"A girl who is light-complectioned."

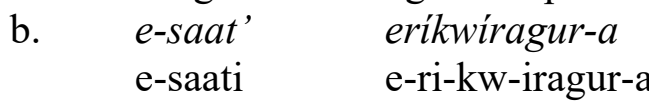
AUG-9.shirt AUG.9.REL-be-INF-black-FV
"A shirt which is black."

Based on the morphosyntactic evidence provided, the word forms examined in this section are nominal relatives with nominal properties contained in a clausal structure. The nominal modifiers examined in this section therefore are not adjectives on the account of the distinct morphosyntactic properties they exhibit. The words which remain under the adjective class show agreement with the noun by taking a copy of the prefix of the noun plus an adjectival root. In the next section, I examine morphosyntactic characteristics of the second category, namely clausal relatives.

\section{Clausal relatives}

A clausal relative is a nominal modifier in the form of a subordinate clause dependent on a matrix clause. Clausal relatives are subcategorised into two: subject and object relatives. First, they are categorised as such because different strategies are involved in their formation. Subject relatives in Runyankore-Rukiga are realised within the noun class prefix, and therefore are not phonological words while object clausal relatives have the status of phonological words, often regarded as pronouns (cf. Taylor 1985). Although subject and object clausal relatives exhibit distinct syntactic properties, there are properties that generally characterize both, as outlined in Asiimwe (2014: 325), e.g.: 6

i. $\quad$ Both use a nominal agreement prefix for relativization;

ii. Both take full nouns as well as phonologically null heads in the case of a familiar or an already introduced nominal referent;

iii. Clausal relatives allow an optional augment (see 11.a) in their morphology, like other nominal modifiers (such as adjectives and possessives);

iv. A modifying relative clause can occur internally in the modified DP or outside the clause containing the modified DP (see section 5);

v. A clausal relative can appear with no explicit head noun.

Although there are common characteristics between subject and object relative clauses, the two categories of clausal relatives present variations in terms of their morphosyntactic properties.

\footnotetext{
${ }^{6}$ For more discussion and illutrations, see Asiimwe (2014).
} 
First, in section 3.1, I discuss subject clausal relatives before turning to object relative clauses in section 3.2 .

\subsection{Subject clausal relatives}

Subject clausal relatives take a syntactic subject as the head. The subject relative forms part of the relative verbal inflection as it modifies a structural subject head of the matrix clause. Similar to most nominal modifiers, clausal relatives share agreement properties with the head noun, and also permit an optional augment (11.a-b). The subject agreement prefixed to the relative subordinate clause doubles as the subject relative clause marker. A subject clausal relative marker is not a phonological word but a bound morpheme that coalesces with the noun class agreement prefix as exemplified in (11.a-b):
a. Abarámbuz'
(á)baagiire
Bwindi
bagarúkire
a-ba-rambuzi
(a)-ba-a-gi-ire
Bwindi
ba-garuk-ire
AUG-2-tourist AUG-2.REL-PAST-go-PFV bwindi
2-return-PAST
"The tourists who went (particularly) to Bwindi returned."
b. Abarámbuz' abaagiire Bwindí bagarúkire

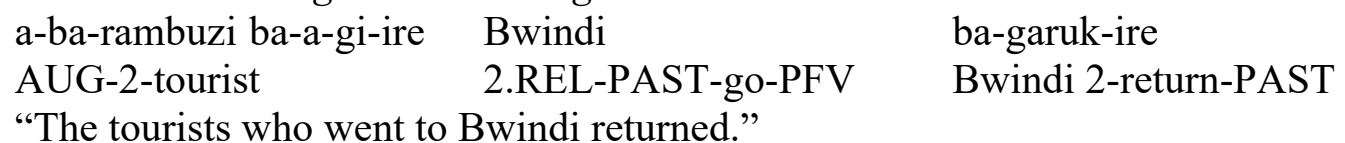

Previous studies on the relative clause in Runyankore-Rukiga (Morris and Kirwan 1972; Taylor 1985) indicate that the strategy used to form subject relatives attaches an augment to the relative verb. While I acknowledge that subject clausal relatives permit an augment, this augment, as data indicates, is not a relative clause marker. A relative meaning can be realized even when the augment is absent (e.g. 11.b). The relative clause meaning is embedded within the agreement prefix realized by differential tone marking. The effect of tone differs based on the tense involved and who is speaking because tone varies according to the variety of RunyankoreRukiga one speaks. The illustrations in (12.a-b) show differential tone marking in realizing either a full independent clause or a relative clause. Realization of either a full clause or a relative clause as a result of variation in tone marking is only possible with the immediate past and recent past. The immediate past tense in Runyankore-Rukiga is marked by $-a a$ - and the recent past by -ire (Taylor 1985; Turamyomwe 2011).

$\begin{array}{lll}\text { a. } & \text { Embwá } & \text { záámoka } \\ \text { e-n-bwa } & \text { z-aa-mok-a } \\ \text { AUG-10-dog } & \text { 10-PASTIM-bark-FV } \\ \text { "Dogs have barked." } \\ \text { b. } & \text { embwa } & \text { záámoka } \\ & \text { e-n-bwa } & \text { z-aa-moka } \\ & \text { AUG-10-dog } & \text { 10- PASTIM-bark-FV } \\ & \text { "dogs which have barked" } \\ \text { a. } & \text { Embwá } \quad \text { zimokire } \\ & \text { e-n-bwa } \quad \text { zi-mok-ire } \\ \text { AUG-10-dog } & \text { 10-bark-PFV } \\ & \text { "Dogs barked." }\end{array}$




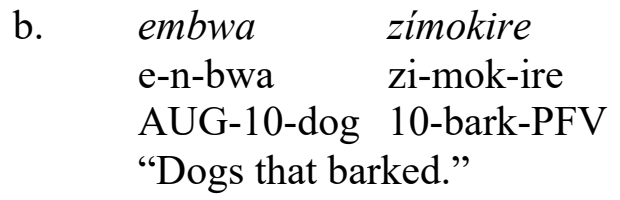

Tone is therefore significant in the formation of subject clausal relatives. As indicated in (12.a) in the immediate past tense, the final vowel of the structural head noun takes a high tone and the tense marker too bears a high tone for full clause formation. For relative clause formation, in (12.b) the concord and tense take a high tone, while it is only the tense marker that bears a high tone. In the recent past tense, the high tone shifts to the first vowel of the tense/perfective aspect marker -ire but also the final vowel of the subject head, as illustrated in (13.a) to form a full clause. For a relative clause formation, the vowel of the noun class carries a high tone and the rest of the units are toneless. Based on the data provided here, we cannot conclude that it's the vowel of the noun class prefix which bears the high tone for relative clause formation. The high tone can even appear on a vowel within the verb root (14), when the structural subject noun exemplified in (13) changes to singular form.

$$
\begin{array}{ll}
\text { embw' } & \text { emókire } \\
\text { e-m-bwa } & \text { e-mók-ire } \\
\text { AUG-9-dog } & \text { 9-bark-PFV } \\
\text { "The dog which barked." }
\end{array}
$$

The available data shows that we cannot predict which unit will bear a high tone. It appears that the high tone shifts to form either a full clause or a relative clause, and is determined by a number of factors including tense and aspect, number, number of tone bearing units in the verb complex, the noun class of the subject head, and the variety of Runyakore-Rukiga one speaks. For this paper, I cannot provide a detailed investigation of the role of tone in the formation of relative clauses. This requires a separate study.

We have noted above that the augment does not encode clausal relative meaning. A clausal relative meaning can still be accessed even when the augment is absent, as discussed in section 4. Instead, the augment expresses restriction, while its absence entails a non-restrictive reading.

There are some constraints to the optional use of the augment in subject relative clause structures. Noun classes whose agreement prefixes are in the form of a consonant plus a vowel, allow an optional augment. Those that are in the form of a vowel only, such as nouns in classes 1 and 9 where the initial morpheme of the clausal verb is of a portmanteau nature (e.g. in 15),

\begin{tabular}{|c|c|c|c|}
\hline $\begin{array}{l}\text { Omunyankór' } \\
\text { (Mubangizi 1997: }\end{array}$ & $\begin{array}{l}o g w^{\prime} \\
20)\end{array}$ & ótarikumanya & Ruganda \\
\hline o-mu-nyankore & o-gu & o-ta-ri-ku-many-a & 11.Ruganda \\
\hline AUG-1-nyankore & DEM-1.this & 1.REL-NEG-be-INF-know-FV & Ruganda \\
\hline
\end{tabular}
take an obligatory augment which doubles as the subject relative clause marker. It is therefore obligatory since the subject marker is an obligatory element in the verbal template.

The subject agreement prefix for nouns in class 1 in a subject relative clause construction is $o$ as indicated in (15). However, the available data shows that there is a tendency nowadays for 
some speakers, especially Runyankore speakers, to replace the $o$ - vowel with $a$ - (16) as observed in the spoken discourse.
O-mu-nyankore
$o g w^{\prime}$
atarikumanya
Ruganda
o-mu-nyankore
$\mathrm{o}-\mathrm{gu}$
a-ta-ri-ku-many-a
Ruganda
AUG-1-nyankore DEM-1.this 1. REL-NEG-be-INF-know-FV
"A Munyankore who does not speak Luganda."
11.Ruganda

As indicated in the two examples given in (15) and (16), there is a morpheme change from $o$ to $a$ - as a subject agreement prefix which doubles as the relative clause marker and this leads to anti-agreement. This change may be attributed to language contact. There is close contact between Runyankore-Rukiga and Luganda ${ }^{7}$. As a result, there is a lot of lexical borrowing from Luganda to Runyankore-Rukiga. In addition, Luganda has an influence on the grammatical structure of Runyankore-Rukiga and other Ugandan indigenous languages. In Luganda, the agreement marker for nouns in class 1 in subject relatives is $a$-. There is generally an observed influence of Luganda on other typologically related languages spoken in Uganda. However, the scope of the current paper does not allow a detailed analysis of language change due to language contact with respect to Runyankore-Rukiga and Luganda. In the next section, I discuss the structure of object relative clauses.

\subsection{Object clausal relatives}

Object clausal relatives involve relativization of structural objects. Runyankore-Rukiga possesses a free standing obligatory element that marks an object relative clause. As mentioned already, similar to subject clausal relatives, object clausal relatives agree with the structural subject (17). The object clausal relative agrees with the relativized object (see more on agreement in the next section). In (17.a), the object relative clausal marker takes an augment while the augment is missing in (17.b). The role of the augment in the inflectional morphology of clausal relatives is discussed in the next section.

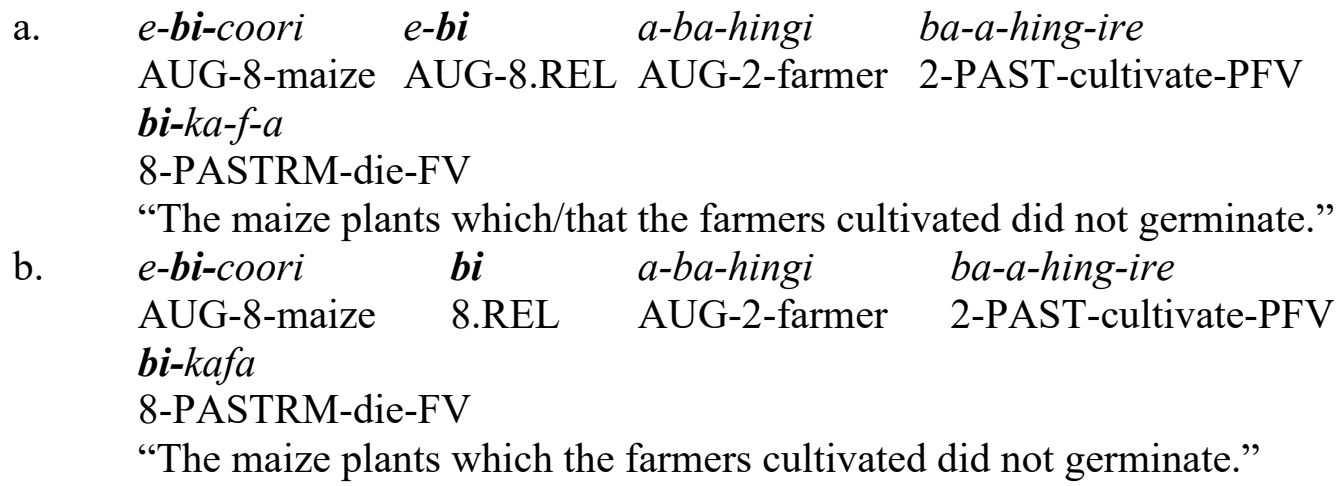

There are two pertinent questions that this paper attempts to answer with regards to the status of the object relative marker in the Runyankore-Rukiga language cluster. First is the question as to whether or not the object relative marker is a relative pronoun corresponding to the English wh- relative pronouns, as has previously been claimed. Second is the question concerning

\footnotetext{
${ }^{7}$ Luganda spoken in the capital Kampala and generally in the central region of Uganda is the indigenous language of the biggest ethnic group in Uganda with the highest number of speakers (Uganda National Population and Housing Census report 2014) compared to other indigenous languages.
} 
whether or not the object relative marker is a demonstrative. I attempt to address these two concerns in turn.

A number of studies on Bantu languages have equated the object relative clause marker to the English wh- relative pronouns. Therefore, this subsection examines the question as to whether or not the relative clause marker is a relative pronoun in Runyankore-Rukiga. In consideration of studies on Bantu relative clause constructions, Henderson (2006), Zeller (2004), and Walusimbi (1976), among others refer to the object relative clause marker as a pronoun. For Runyakore-Rukiga, Taylor (1985) considers it a relative pronoun as well. However, there are studies which do not entirely agree with this school of thought. For instance, Cocchi (2004) argues that there are no relative pronouns in Bantu languages to correspond with the English wh- pronouns. Kinyalolo (1991) too contends that there are no overt relative pronouns in Bantu languages and argues that a relative clause pronoun is an abstract one represented by a phonologically null form. Relatedly, Cheng and Downing (2007: 53) assert that there are no relative pronouns in Zulu, a Bantu language of South Africa. In this paper, my argument follows that of Demuth and Harford (1999) who state that an object clausal relative marker in Runyankore-Rukiga is not a relative pronoun. Rather, it is an agreement-bearing complementizer. An object clausal relative marker stands as a full-fledged lexical item to encode relative meaning (see Asiimwe 2014: 332). The object relative clause marker is an agreement-bearing lexical item that heads the relative clause which forms a complementizer phrase (CP). Henderson (2006) seems to suggest that the object relative marker is a pronoun when it stands as an independent phonological unit. On the other hand, if it appears as an affix attached on the verb, Henderson regards that as a complementizer. Compare (18.a) and (18.b):

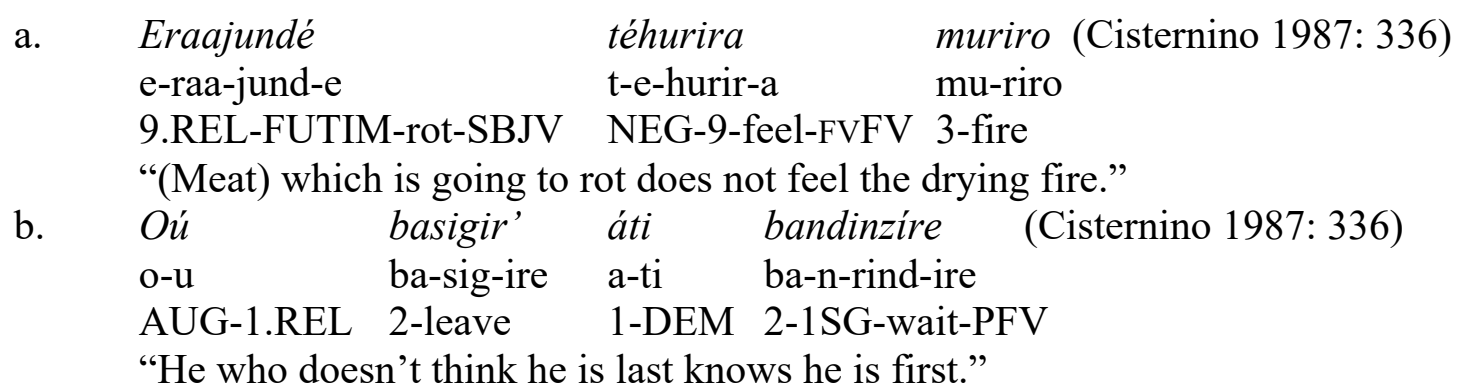

Henderson's (2006) exposition regarding the categorial status of clausal relative markers does not hold for Runyankore-Rukiga whose subject relatives are affixes (18.a) while the object relative markers are stand-alone morphological words (18.b). It would mean that object relative clause markers are pronouns because they are independent morphemes while subject relative clause markers are complementizers. Data from Runyankore-Rukiga would necessitate a different analysis. The view taken in this paper is that a CP can be headed by either an object or a subject relative clause. The difference is that the object clausal relative is headed by a phonological word, while the head of a subject clausal relative is phonologically null.

The second question concerns whether or not the object relative clause marker is a demonstrative. Wald (1973), Henderson (2006), Zeller (2006), and Visser (2008) among others argue that the Bantu relative complementizer has its source in the demonstrative. This, however, may not be a conceivable idea for Runyankore-Rukiga. Following Asiimwe (2014, 2016), I argue that demonstratives exhibit deictic and anaphoric features, and hence, they are inherently definite. The object clausal relative does not exhibit any of these properties intrinsic to the 
demonstrative. A noun modified by a relative clause headed by a relativizer is not necessarily definite as would be expected if the object clause relative had connections with the demonstrative. Instead, a definite reading is dependent on an appropriate discourse-pragmatic context.

Although the object clausal relativizer resembles the demonstrative, it does not possess similar semantic features to the demonstrative. However, one may alternatively argue that the object clausal relative evolved from the demonstrative, and is in the process of grammaticalization to become a clausal relative maker. It therefore lost its semantic features of identifying a familiar referent through deixis and anaphoricity. One question to ponder about, however, queries why the subject clausal relative is different in form and structure from the object clausal relative marker. Recall that subject clausal relatives are not phonologically independent like object relative markers (see section 3.1). For now, I propose, following Asiimwe (2014), that a relative clause marker should be taken as an agreement-bearing complementizer heading a Complementizer Phrase (CP).

Observe in Table 1 that not all object clausal relatives are similar in form to the proximal demonstrative forms. This poses another challenge as to whether or not object clausal relative markers should be analyzed as demonstratives. Otherwise, one would expect all relative clause markers to resemble their demonstrative counterparts, which is not the case.

\begin{tabular}{|l|c|c|}
\hline Noun class & $\begin{array}{c}\text { Proximal } \\
\text { demonstrative forms }\end{array}$ & $\begin{array}{c}\text { Object clause } \\
\text { relative forms }\end{array}$ \\
\hline 1 -mu- & ogu (a-gu) & (o)u \\
\hline 2 -ba- & aba (a-ba) & (a)bu \\
\hline 3 -mu- & ogu (a-gu) & (o)gu \\
\hline 4 -mi- & egi (a-gi) & (e)i \\
\hline 5 -ri- & eri (a-ri) & (e)ri \\
\hline 6 -ma- & aga (a-ga) & (a)gu \\
\hline 7 -ki- & eki (a-ki) & (e)ki \\
\hline 8 -bi- & ebi (a-bi) & (e)bi \\
\hline 9 -n- & egi (a-gi) & (e)i \\
\hline 10 -n- & ezi (a-zi) & (e)zi \\
\hline 11 -ru- & oru (a-ru) & $($ o)ru \\
\hline 12 -ka- & aka (a-ka) & (a)ku \\
\hline 13 -tu- & otu (a-tu) & (o)tu \\
\hline 14 -bu- & obu (a-bu) & (o)bu \\
\hline 15 -ku- & oku (a-ku) & (o)ku \\
\hline 16 -ha- & aha (a-ha) & (a)hu \\
\hline 17 -ku- & oku (a-ku) & (e)i \\
\hline 18 -mu- & omu (a-mu) & (o)mu \\
\hline
\end{tabular}

Table 1: Comparison of proximal demonstrative forms with the forms of the object clausal relative markers. Adapted from Asiimwe (2014: 333)

I further consider the initial element of the demonstrative (which is underlyingly $a$-) as the core morpheme of the demonstrative (19.a) attested in many Bantu languages (cf. Wald 1973; Visser 
2002, 2008; Asiimwe 2014, 2016). We have already noted that the augment of relative clause markers is not an integral part of the relativizer as it can be dropped ((19.b); also see section 4). This then means that the augment attached to object clausal relatives bears distinct (pragmatic) features from those of the initial morpheme of the demonstrative which semantically bears the core roles of deixis and anaphoricity which are intrinsic in the demonstrative. Since the augment is optional, it may be due to grammaticalization that in the process of evolution, it lost some of the properties exhibited in the core morpheme of the demonstrative (see Asiimwe 2016). Synchronically, the augment offers discourse-pragmatic functions.
a. Tindikwend'
ti-n-ri-ku-end-a
ék'
a-ki
ékitabo (Asiimwe 2014: 181)
NEG-1SG-be-INF-want-FV
DEM-7.this AUG-7-book
"I do not want this book."
b. mbuganaho
167)
n-bugan-a $=$ ho
o-mu-ojo u n-ri-ku-many-a
1SG-meet-FV=16.ENC AUG-1-boy1.REL 1SG-be-INF-know-FV
omwojo ú ndíkumanya (Mubangizi
1997:
"I met there a boy whom I know."

The subtle resemblance is between the object clausal relative marker and the first degree of distance demonstratives. There is no connection in the structure of the demonstrative for second and third positions and the relative clause marker, as shown in Table 2 below:

\begin{tabular}{|l|c|c|c|c|c|}
\hline Noun class & $\begin{array}{c}\text { Object clause } \\
\text { relative marker }\end{array}$ & Proximal & Medial & \multicolumn{2}{|c|}{ Distal } \\
\cline { 4 - 6 } & (o)u & ogu (a-gu) & ogwo (ou-o & O-risible & Invisible \\
\hline 2 -ba- & (a)bu & aba (a-ba) & abo (a-ba-o) & ba-riya & o-ri \\
\hline 3 -mu- & (o)gu & ogu (a-gu) & ogwo (a-gu-o) & gu-riya & gu-ri \\
\hline 4 -mi- & (e)i & egi (a-gi) & egyo (a-gi-o) & gi-riya & gi-ri \\
\hline 5 -ri- & (e)ri & eri (a-ri) & eryo (a-ri-o) & ri-riya & ri-ri \\
\hline 6 -ma- & (a)gu & aga (a-ga) & ago (a-ga-o) & ga-riya & ga-ri \\
\hline 7 -ki- & (e)ki & eki (a-ki) & ekyo (a-ki-o) & ki-riya & ki-ri \\
\hline 8 -bi- & (e)bi & ebi (a-bi) & ebyo (a-bi-o) & bi-riya & bi-ri \\
\hline 9 -n- & (e)i & egi (a-gi) & egyo (a-gi-o) & e-riya & e-ri \\
\hline 10 -n- & (e)zi & ezi (a-zi) & ezo (a-zi-o) & zi-riya & zi-ri \\
\hline 11 -ru- & (o)ru & oru (a-ru) & orwo (a-ru-o) & ru-riya & ru-ri \\
\hline 12 -ka- & (a)ku & aka (a-ka) & ako (a-ka-o) & ka-riya & ka-ri \\
\hline 13 -tu- & (o)tu & otu (a-tu) & otyo (a-tu-o) & tu-riya & tu-ri \\
\hline 14 -bu- & (o)bu & obu (a-bu) & obwo (a-bu-o) & bu-riya & bu-ri \\
\hline 15 -ku- & (o)ku & oku (a-ku) & okwo (a-ku-o) & ku-riya & ku-ri \\
\hline 16 -ha- & (a)hu & aha (a-ha) & aho (a-ha-o) & ha-riya & ha-ri \\
\hline 17 -ku- & - & oku (a-ku) & okwo (a-ku-o) & ku-riya & ku-ri \\
\hline 18 -mu- & (o)mu & omu (a-mu) & omwo(a-mu-o) & mu-riya & mu-ri \\
\hline
\end{tabular}

Table 2: List of demonstratives in Runyankore-Rukiga adapted from Asiimwe (2014: 185) 
The next section discusses the use of the augment in relative constructions with the purpose of showing that the augment does not express relative meaning but leads to a restrictive reading of the relative clause.

\section{The augment in clausal relative formation}

The augment in relative clause constructions in Runyankore-Rukiga is optional as has already been exemplified. This argument is contrary to the claim made by Morris and Kirwan (1972) and Taylor (1985) that the augment in subject relative clause encodes a relative meaning. In both subject and object clausal relatives, the relative clausal meaning is encoded in the nominal class prefix. In addition, a subject relative clause is differentiated from a full clause by differential tone marking, as discussed in section 3.1. The presence of the augment is related to information-structure encoding. In other words, an augment induces a restrictive interpretation. This also means that the presence of the augment signals that there is a particular entity that the speaker has in mind selected from other entities with the same semantics (Asiimwe 2014).

To test the hypothesis that the presence of the augment is to encode a restrictive relative clause while its absence entails a non-restrictive reading of a relative clause, the question word 'which' is used. Question words are used as one way of testing restrictiveness or exclusive focus as a category of information structure (van der Wal 2016). A question word (such as who, which, where) typically selects a focused referent in a clause. The presence of the augment (20.b) is preferred on a relative clause in the answer to the question posed in (20.a), as it typically selects one eagle out of the rest of the accessible eagles. When the augment is absent, it means that there are no alternatives implied, hence there is no restriction made. It is infelicitous to respond as in (20.c) $)^{8}$ with no augment on the subject relative to the question posed in (20.a), since selection has to be made from potential referents.

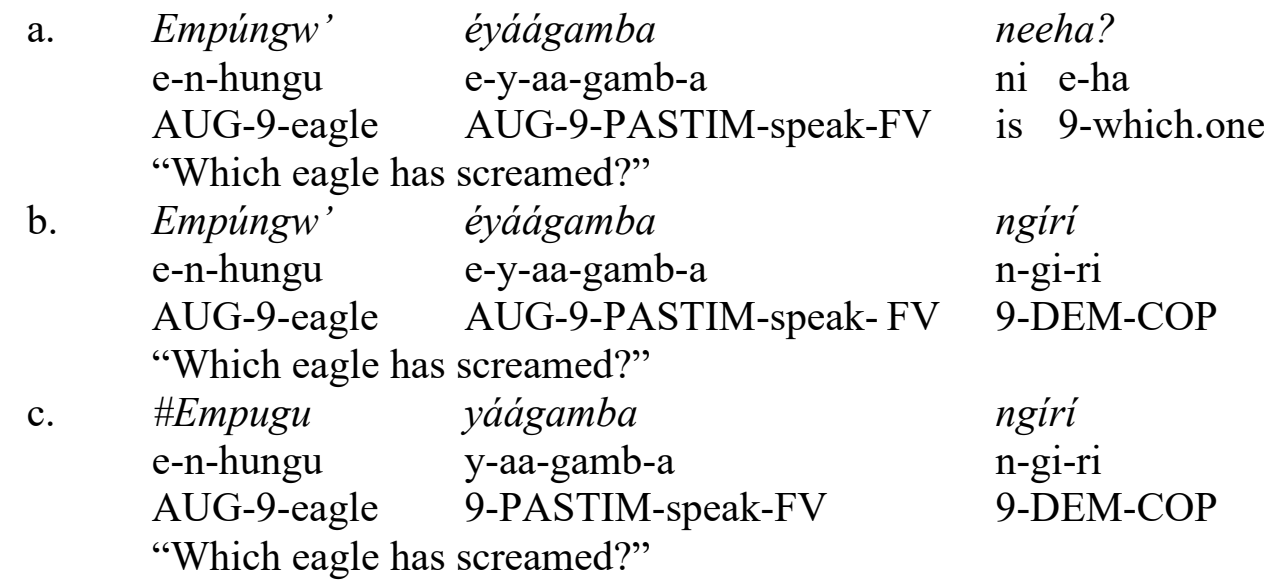

The role of the augment expressing a restrictive meaning in relative clauses is further demonstrated in the comparison between (21.a) and (21.b). The illustrations in (21.a-b) exemplify object relative clauses. The augment is absent on the relative clause marker in (21.a) while it is present on the object relative marker in (21.b). Its presence leads to a restrictive relative clause interpretation of the noun, ekanisa. In this instance, the augment selects one

\footnotetext{
${ }^{8}$ The symbol \# means that the sentence is grammatical but not an appriprite response to the question in (20.a) due to the absence of the augment.
} 
referent ekanisa built particularly by Bakiga and also signals that there are other churches built by other builders, which it excludes.
a.
Nibakunda ekanisa yabakiga van der Wal 2019) ${ }^{9}$
Ni-ba-kunda e-kanisa i
i Abakiga
baayómbekire (Asiimwe
and
PROG-2-like AUG-church 9.REL
2.Abakiga
ba-aa-yombek-ire
"They like the church, which the Bakiga constructed."
b. Nibakunda ekanis' eyabakiga baayómbekire
Ni-ba-kunda e-kanisa e-i Abakiga ba-a-yombek-ire
PROG-2-like AUG-church AUG-9.REL 2.Abakiga SM-PAST-build-PFV
"They like the church that/which the Bakiga constructed."

The augment is not a central part of the relative clause marker both in subject and objective relative clauses. Given the right context, it can either be omitted (e.g., 21.a) or retained (21.b). Previous studies associate the augment that appears with subject relative clauses in Runyankore-Rukiga to definiteness (Taylor 1985). The presence of the augment does not lead to a definiteness reading. As illustrated above, the augment realizes a restrictive reading of the relative clause. In other words, it expresses exclusive focus such that its absence is due to the fact that there are no other entities to select from. The speaker in (21.a), for instance, has one church in mind while in (21.b), the speaker uses the augment as a strategy to select one church and exclude the rest of the churches.

In a bid to provide further evidence against the claim that the augment is a relative clause maker, I demonstrate that the augment can be affected by negation the same way as appears with other nominals bound by a negative operator. For grammatical reasons, a nominal element that immediately follows the negative indefinite pronoun tihaine/tihariho ${ }^{10}$ 'nobody/none' in an existential construction is supposed to lose its augment as illustrated in (22.a-22.b). The noun that immediately follows tihaine loses the augment in the same way that the relative clause that immediately follows the same word does (compare 22.a and 22.b). In (22.b), the noun immediately follows tihaine and loses the augment while the relative clause that follows the noun appears with an augment. In (22.c), the elements are reversed, so that the relative clause which now immediately follows the expletive tihaine loses the augment while it is obligatorily retained on the noun that follows. The negative effect usually does not spread beyond the element that immediately follows the negative verb. Hence, the augment on the relative clause (in 20.b), if left out, does not have an effect on the grammaticality of the construction.

$\begin{array}{llll}\text { a. } & \text { harih' abantu } & \text { Marugire } & \text { Misiri (Okubara 22: } 11 \\ \text { Runyankore-Rukiga Bible) } & & \\ \text { hariho a-ba-ntu } & \text { ba-rug-ire } & \text { Misiri } \\ \text { 'there.are AUG-2-person } & \text { 2-come.from-PFV egypt' } \\ \text { "A people that has come out of Egypt." (Bible Numbers 22:11 NIV) } & \end{array}$

\footnotetext{
${ }^{9}$ Data from a field study conducted in January 2019, in Kabale district, Uganda.

${ }^{10}$ The words haine and hariho which both mean 'there is' are used interchangeably in the Runyankore-Rukiga Bible of 1964. However, hariho is not interchangeable with haine in all contexts. For instance, in: Hakaba hariho. 'There was...'. Asiimwe (2014) discusses the usage of the two closely related expletives with regards to (in)definiteness and specificity in Runyankore-Rukiga.
} 


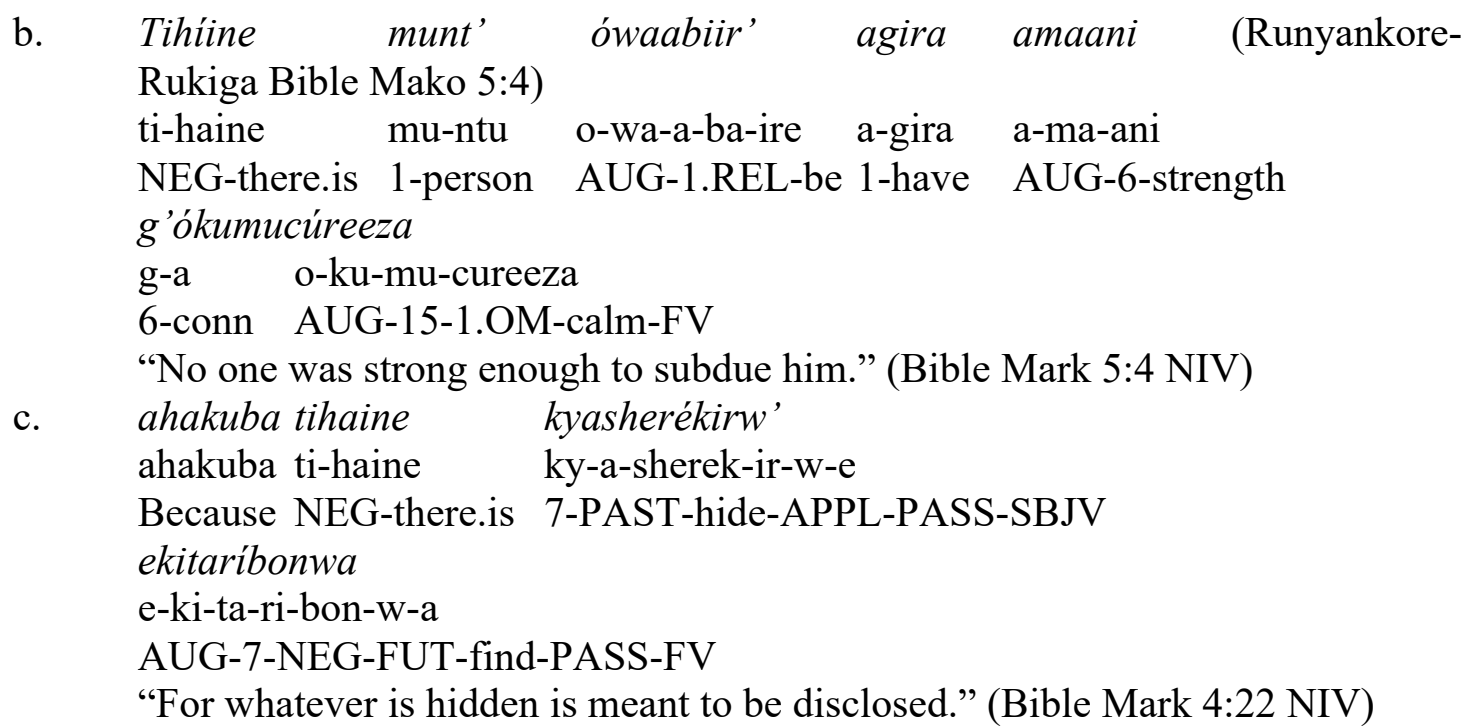

The indefinite or expletive haine/hariho 'there is' requires a relative clause to modify the head noun. In the affirmative, the expletive haine/hariho requires the relative clause marker to appear with the augment (22.a).

The foregoing explanation and the examples given in (22.a-c) are aimed at providing more evidence that the augment is not an integral part of relative clause markers, but an optional element permitted generally by nominals in Runyankore-Rukiga. Next, I explore the phenomenon of agreement in relative clauses.

\section{Agreement and word order in clausal relative constructions}

Agreement in relative clauses has been discussed for other Bantu languages (e.g. Henderson 2006, Demuth and Harford 1999; Zeller 2004; Simango 2006 among others). A clausal relative canonically follows the subject head noun of the matrix clause and agrees with the matrix verb as exemplified with an object relative clause structure (23). The agreement bearing complementizer also agrees with the relativized object head ebicoori 'maize'.

$\begin{array}{llll}\begin{array}{l}\text { Ebicoor' } \\ \text { e-bi-coori ébyabahíngi }\end{array} & \text { e-bi } & \text { a-ba-hingi } & \begin{array}{l}\text { bahire } \\ \text { ba-a-hing-ire }\end{array} \\ \text { AUG-8-maize } & \text { AUG-8.REL } & \text { AUG-2-farmer } & \text { 2-PST-cultivate-PFV } \\ \text { bikáfa } & & \\ \text { bi-ka-f-a } & & \\ \text { 8-PASTRM-die-FV } \\ \text { "The maize that/which the farmers planted did not germinate." }\end{array}$

There is a free word order, such that the clausal relative can be moved out of its internal position (24.a-b). Hence, a dependent clausal relative can appear inside the main clause (23), in the initial position (24.a), and in the final position outside the matrix clause (24.b). Whichever position the dependent clausal relative assumes, it is expected that the structural subject maintains agreement with the relative complementizer and the matrix verb while the subject of the dependent clause maintains agreement with its predicate. 


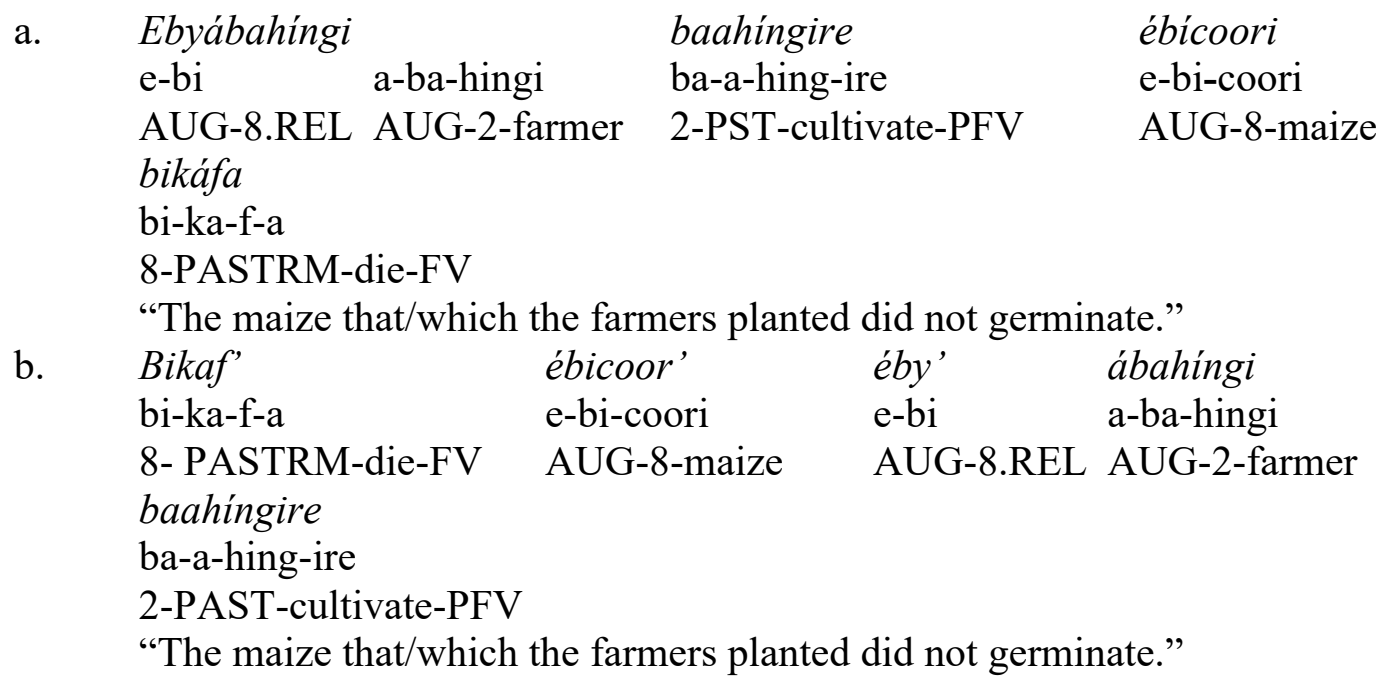

The occurrence of a clausal relative preceding the relativized head noun (ebicoori) (23) signals that subject inversion is possible (for pragmatic or information structural encoding) with clausal relatives. Even when the subject is inverted, it is expected to trigger agreement on the verb of the relative clause. However, there are some exceptions with regards to the phenomenon of agreement. We observe anti-agreement in some instances. For example, in (25), typically one would expect $a h u$ instead of $e i$ in the clause ei arikuza 'where he was going'. Locative head nouns are expected to take a locative class 16 or 18 agreement $(-h u /-m u)$ depending on the semantics of the head noun. Nevertheless, either a locative agreement prefix or $e i$ which is the agreement prefix for class 9 nouns can be used even when $e-i$ seems to agree more with a concrete internal head noun such as ensi 'place' as seen in the clause ...omu nsi ei yaabaire naaza kuheebwa ... 'a place he would later receive as his inheritance' (25). The prefix $e-i$ is preferred in the extract in (25) because it marks a wider unspecified area (what the clause implies) than $a-h u$ which refers to a more confined place (cf. Beermann and Asiimwe, forthcoming). Hence, even when the two agreement prefixes, that is, $a h u$ and $e i$, can be interchanged, the semantics of the modified head noun has to be considered.

(25) Ahabw'ókwikiriza, Ábrahamu kú yaayesirwe kuruga ówáábo kuza omu nsi éi yaabaire naaza kuheebwa kuba óbuhunguzi akóóroba yaarugayo atarikumanya éi aríkuza. (Abaheburaayo 11:8 Runyankore-Rukiga Bible)

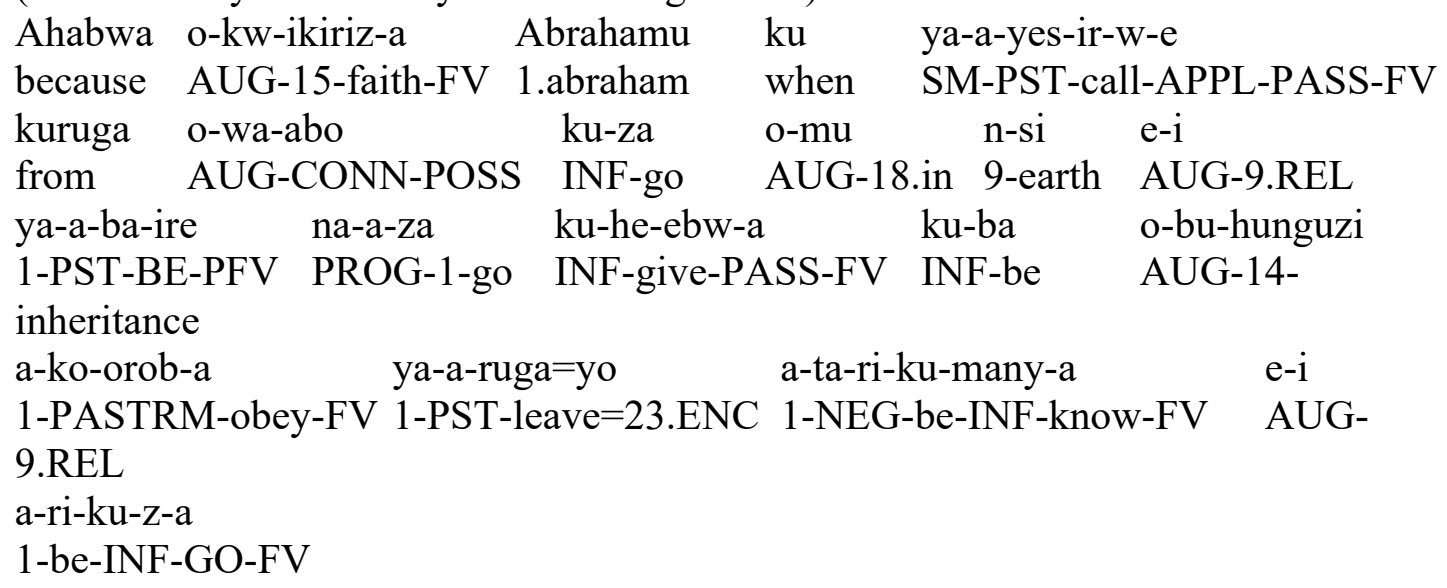


"By faith Abraham, when called to go to a place he would later receive as his inheritance, obeyed and went, even though he did not know where he was going." (Bible Hebrews 11:8 NIV)

Further note that when the antecedent of a relative clause is a locative phrase (as in 23), agreement may occur with either the internal locative noun or the initial locative element which is often termed a preposition (Morris and Kirwan 1972; Taylor 1985; but also see Beermann and Asiimwe (forthcoming) for an alternative view). In (26.a), the internal noun $n s i$ agrees with the relativizer $e i$. This is termed in literature as inner agreement (Creissels 2011; Marten 2012; Caha and Pantecheva 2015; Zeller 2017; Beermann and Asiimwe forthcoming, among others). In (26.b) the head of the locative phrase, which is a preposition-like element agrees with the relativizer, and hence the outer agreement. Agreement switch is therefore possible in relative clause constructions involving locative object antecedents. Note further that the initial locative element triggers a compulsory agreeing locative enclitic $-m u$ on the relative clause verb (26.a). When the locative element is in agreement with the object clausal relative marker, the verb does not take a locative enclitic as illustrated by an ungrammatical construction in (26.c). From an observational point of view, it appears that inner agreement is more prevalent than outer agreement and that outer agreement happens when the speaker wants to be more specific with the location.
a. $\quad$ omu
o-mu
n-si
$n s$ 'éi
yaazaariirwému
e-i ya-a-zaar-iir-w-e $=$ mu
AUG-18in 9-earth
AUG-9.REL
b. omu
$n s^{\prime}$ ómú
nsi o-mu
yaazááriirwe
omu

\section{o-mu}
ya-a-zaar-iir-w-e
AUG-18.in 9.earth AUG-18.REL 1-PAST-born-APPL-PASS-SBJV
"In the land where he was born."
c. *omu
ns'omu
o-mu nsi o-mu
yaazaariirwemu
AUG-18.in 9.earth AUG-18.rel
ya-a-zaar-iir-w-e $=$ mu
Intended: "In the land where he was born."

Following Demuth and Harford (1999), agreement occurs to the element that has been raised to SPEC-IP. The agreement switch phenomenon signifies that either the internal locative noun or the locative head can move to the spec-IP. This phenomenon is further exemplified in (27.ad).
a. ah'iziba
a-ha
áhú
i-ziba a-hu
twataha
ámiizi
AUG-16.at 5-well AUG-16.REL
1PL-PASTIM-fetch-FV AUG-6-water
"At the well where we fetched water."
b. iziba
érí
twatahahw'
e-i-ziba
e-ri
tw-aa-tah-a $=$ ho
ámíizi
AUG-5-well AUG-5.REL 1PL-PASTIM-fetch-FV=16.ENC AUG-6-water
"The well at which we fetched water." 


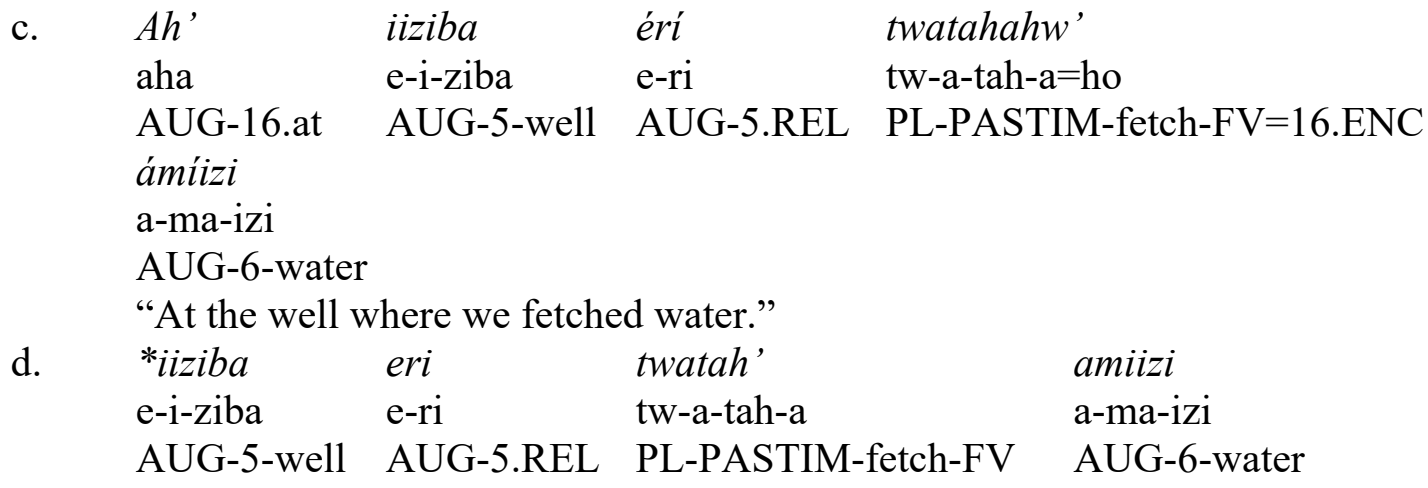

The illustration in (27.a), shows that the locative element ( $a h a)$ in the prenominal position is in agreement with the object clausal relative marker that stands at the beginning of the relative clause. In addition, in the main clause without the locative element $a h a$, a locative enclitic is obligatory (27.b). Without the enclitic, the construction turns out ungrammatical (27.c). Omu (class 18) is expected to trigger omu as an object clausal marker, aha (class 16) goes with $a h u$ as the object clausal marker, while $e i$ as an object relative clause marker would be to come about when the locative element is $o-k u$ (class 17) but $o k u$ is never used before a locative noun ${ }^{11}$. Again, $e i$ is the agreement prefix for nouns in class 9. It is expected that the class 18 locative head oти in (28) should trigger omu as the object relativizer. We instead see $a h u$ for class 16 nouns. It is acceptable for $a h u$ (class 16) to co-occur with omu (class 18). This is possible perhaps due to the fact that the class 16 concord is more prevalent, and moreover the only verbal pronominal concord in Runyankore-Rukiga (Taylor 1985; Beermann and Asiimwe forthcoming).

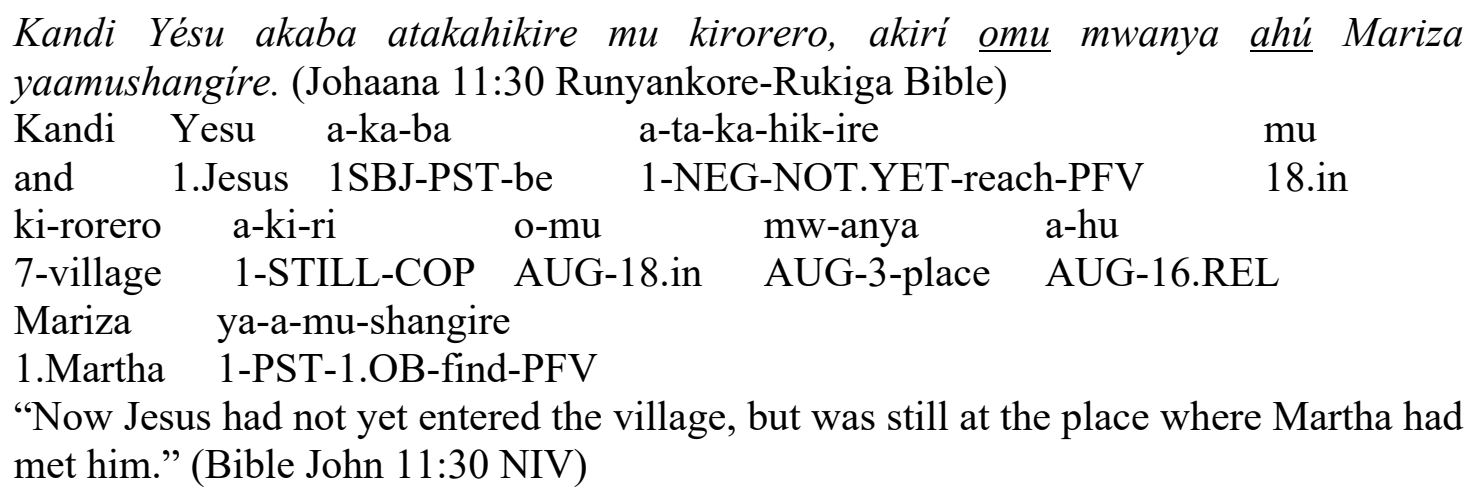

Locatives present interesting properties as regards relative clause marking especially when the phenomenon of agreement switch is considered. For topical reasons, an object noun or the locative element (aha/omu) triggers agreement with the relativivizer and is moved to occupy the Spec-position. However, it is important to note that agreement alternation properties are dependent on the type of relativized noun. It appears that the phenomenon is common with relative locative objects.

\footnotetext{
${ }^{11} \mathrm{Oku}$ (class 17) is less productive in the language cluster.
} 


\section{Conclusion}

The aim of this paper was to describe key morphosyntactic features of relative clause constructions in Runyankore-Rukiga. Studies on relative clause formation strategies have been conducted for individual languages, and a number of comparative studies have been carried out as well (such as Henderson 2006, 2007; Demuth and Harford 1999; Zeller 2004; Riedel 2010). Although Bantu languages are typologically related, they still present fine-grained variations in many aspects. This study does not only contribute data for typological and comparative studies, but also offers data for formal theoretical studies.

I have discussed key aspects as regards relative clause constructions in Runyankore-Rukiga. But before that, I have categorized relatives into two groups, that is, nominal and clausal relatives. Lexical elements placed in the category of nominal relative have previously been regarded as adjectives. On the account of their morphosyntactic structure, they differ from 'true' adjectives. I have argued that these elements possess both nominal and clausal features and therefore are distinct from adjectives. The second category comprises the clausal relatives which are further subcategorized into subject and object clausal relatives. A subject clausal relative is encoded within the agreement prefix attached on the relativized verb through differential tone marking. The current study could not examine the role of tone in subject relative clause formation in detail. However, this would be an interesting phenomenon to pursue. Object clausal relatives, on the other hand, are marked through a free standing morpheme which previous scholars have regarded as a relative pronoun. In this paper I offer an alternative analysis that the object relative clause marker is an agreement-bearing complementizer heading a CP but not a relative pronoun. Based on the evidence provided in section 3.2, this study further asserts that the object relative clause marker in RunyankoreRukiga is not a demonstrative. Data indicates that the object relative marker and the demonstrative present distinct semantic features. However, a more in-depth study needs to be carried out to ascertain whether the object relative clause marker evolved from the demonstrative through grammaticalization.

As discussed in section 4, the augment is not a relative clause marker since it can be omitted while the relative meaning is retained. Its presence serves to differenciate a restrictive reading from a non-restrictive intepreation of a relative clause. Agreement properties are another aspect that I have discussed in this paper. Interesting to note is that an object clausal relative marker can either agree with the locative head omu or aha or the internal locative noun. It was further observed that a locative antecedent may trigger agreement with a subject relative to a different noun class. Agreement involving locatives as antecedents is another interesting idea to pursue, especially concerning agreement switch.

\section{References}

Asiimwe, A. 2016. Investigating the connection between the demonstrative and the definite morpheme - $a$ in Runyankore-Rukiga. South African Journal of African Languages 36(1): 6573. https://doi.org/10.1080/02572117.2016.1186898 
Asiimwe, A. 2014. Definiteness and Specificity in Runyankore-Rukiga. PhD dissertation, Stellenbosch University. Available online: http://hdl.handle.net/10019.1/95926 (Accessed 15 August 2018).

Baker, M.C. 2003. Lexical Categories: Verbs, Nouns, and Adjectives. Cambridge: Cambridge University Press.

Beermann, D. and A. Asiimwe. forthcoming. Locatives in Runyankore-Rukiga. In E.M. Bloom Ström, R. Guérois, H. Gibson and L. Marten (eds.) Approaches to Morphosyntactic Variation in Bantu. Oxford: Oxford Univeristy Press.

Caha, P. and M. Pantcheva. 2015. Locatives in Shona and Luganda. Lingbuzz.

Cheng, L. and L.J. Downing. 2007. The prosody and syntax of Zulu relative clauses. SOAS Working papers in Linguistics 15: 51-63.

Cisternino, M. 1987. The Proverbs of Kigezi and Ankore (Uganda). Kampala: Comboni Missionaries.

Cocci, G. 2004. Relative clauses in Bantu Languages: affixes as relative markers. Rivista di Grammatical Generativa 26: 61-84.

Creissels, D. 2011. Tswana locatives and their status in the inversion construction. Africana Linguistica 17: 33-52. https://doi.org/10.3406/aflin.2011.993

Demuth, K. and C. Harford. 1999. Verb raising and subject inversion in comparative Bantu. Journal of African Languages and Linguistics 20(1): 41-61. https://doi.org/10.1515/ jall.1999.20.1.41

Dixon, R.M.W. 2004. Adjectives classes in typological perspective. In R.M.W. Dixon and A.Y. Aikhenvald (eds.) Adjective Classes: A Cross-Linguistic Typology. Oxford University Press. pp. 1-49. https://doi.org/10.1075/fol.13.1.06bec

Ekitabo ekirikwera ekya Ruhanga ekirikwetwa Baibuli Erikwera: erimu Endagaano eya ira n'Ensya. 1964. (Translated by A.C. Stanley Smith et al.). Kampala: Bible Society of Uganda.

Henderson, B. 2006. The Syntax and Typology of Bantu Relative Clauses. PhD dissertation, University of Illinois.

Kuteva, T.A. and B. Comrie. 2006. The typology of relative clause formation in African languages. In F.K. Erhard Voeltz (ed.) Studies in African Linguistic Typology. Amsterdam: John Benjamins. pp. 209-228. https://doi.org/10.1075/tsl.64.12kut

Kinyalolo, K. 1991. Syntactic Dependencies and the Spec-head Agreement Hypothesis. PhD dissertation, University of California.

Koopman, H.J., D. Sportiche and E.P. Stabler. 2014. An Introduction to Syntactic Analysis and Theory. Hoboken: Wiley Blackwell. 
Lusekelo, A. and L. Mpabela. 2017. Lexical categories in African languages: The case of adjectives word-class in Nyakyusa. Journal of Language, Technology \& Entrepreneurship in Africa 8(1): 1-30.

Maho, J. P. 2009. The online version of the new updated Guthrie list: A referential classification of the Bantu languages. NUGL Online. Available online:

http://goto.glocalnet.net/mahopapers/nuglonline.pdf (Accessed 07 September 2018).

Marten, L. 2012. Agreement in locative phrases in Luganda. In M. Brenzinger and A.M. Fehn (eds.) Proceedings of the 6th World Congress of African Linguistics. Cologne: Köppe. pp. 433443.

Mojapelo, M.L. 2014. Morphosyntactic discrepancies in representing the adjective equivalent in African WordNet with reference to Northern Sotho. Available online: https://www.aclweb.org/anthology/papers/W/W14/W14-0149/ (Accessed 21 July 2019).

Morris, F.H. and K.E.R. Kirwan. 1972. Runyankore Grammar. Kampala: East African Literature Bureau.

Mubangizi, B.K. 1997. Abagyenda Bareeba. Memorial Single Volume. Kisubi: Marianum Press.

Newman, P. 2000. The Hausa Language: An Encyclopedic Reference Grammar. New Haven: Yale University Press.

Nurse, D. 2008. Tense and Aspect in Bantu. Oxford: Oxford University Press.

Nurse, D. 2003. Aspect and tense in Bantu languages. In D. Nurse and G. Philipson (eds.) The Bantu Languages. London: Routledge. pp. 90-102. https://doi.org/10.4324/9781315755946-7

Poulos, G. and L.J. Louwrens. 1994. A Linguistic Analysis of Northern Sotho. Pretoria: Via Afrika.

Riedel, K. 2010. Relative clauses in Haya. ZAS Papers in Linguistics 53: 211-225.

Salzmann, M. 2011. Towards a typology of Locative Inversion - Bantu, perhaps Chinese and English - but beyond? Language and Linguistics Compass 5(4): 169-189. https://doi.org/10.1111/j.1749-818x.2011.00270.x

Segerer, G. 2008. Closed Adjective Classes and Primary Adjectives in African Languages. Paris: LLANCAN Publications.

Shopen, T. (ed.) 1985. Language Typology and Syntactic Description. vol. 3. Cambridge: Cambridge University Press.

Simango, S.R. 2006. Verb agreement and the syntax of ciNsenga relative clauses. Southern African Linguistics and Applied Language Studies 24(3): 277-290. https://doi.org/10.2989/ $\underline{16073610609486421}$ 
The Holy Bible: New International Version. 1984. Grand Rapids: Zondervan.

Taylor, C. 1985. Nkore-Kiga: Croon Helm Descriptive Grammars. London: Croon-Helm. https://doi.org/10.1017/s0047404500016213

Turamyomwe, J. 2011. Tense and Aspect in Runyankore-Rukiga. MPhil dissertation, Norwegian University of Science and Technology.

Uganda Bureau of Statistics. 2016. The National Population and Housing Census 2014 - Main Report. Kampala. Available online: https://unstats.un.org/unsd/demographic/sources/ census/wphc/Uganda/UGA-2016-05-23.pdf (Accessed 04 July 2019).

van der Spuy, A. 2001. In defence of the Zulu adjective. South African Journal of African Languages 21: 148-162. https://doi.org/10.1080/02572117.2001.10586523

van der Wal, J. 2016. Diagnosing focus. Studies in Language 40(2): 259-301.

Visser, M. 2002. The category DP in Xhosa and Northern Sotho. South African Journal of African Languages 22(4): 280-293. https://doi.org/10.1080/02572117.2002.10587517

Visser, M. 2008. Definiteness and specificity in the isiXhosa determiner phrase. South African Journal of African Languages 28(1): 11-29. https://doi.org/10.1080/02572117.2008.10587298

Wald, B. 1973. Syntactic change in the lake languages of Northeast Bantu. Studies in African Linguistics 4(3): 237-268.

Walusimbi, L. 1976. Relative Clauses in Luganda. Köln: Rüdiger Köppe Verlag.

Zeller, J. 2017. (In draft). Locatives in Bantu. Available online: http://www.jzeller.de/pdf/Loc.pdf (Accessed 23 July 2019).

Zeller, J. 2004. Relative clause formation in the Bantu languages of South Africa. Southern African Linguistics and Applied Language Studies 22(1-2): 75-93. https://doi.org/10.2989/ 16073610409486361 